\title{
Analisa Perbandingan Koefisien Harga Satuan Bahan Material Pekerjaan Revitalisasi Pasar Rakyat Desa Tanjung Type D
}

\author{
Elvira Handayani, M. Nuklirullah, El Gafur \\ Fakultas Teknik Sipil Universitas Batanghari Jambi \\ Correspondence email: Elvira.handayani2@yahoo.co.id, el.el_elgafur@yahoo.com
}

\begin{abstract}
Abstrak. Untuk menentukan besarnya biaya bangunan rancangan pekerjaan kosntruksi dari suatu bangunan gedung diperlukan suatu acuan dasar. Acuan tersebut adalah analisa biaya konstruksi yang disusun melalui kegiatan konstruksi penelitian produktivitas pekerja di lapangan dan bertujuan untuk meningkatkan efisiensi dan efektivitas kegiatan konstruksi suatu pembangunan. Analisa biaya konstruksi sering disebut dengan analisa harga satuan pekerjaan. Batasan masalah pada Penelitian ini adalah Pengamatan dilakukan secara langsung pada pekerjaan Revitalisasi Pasar Rakyat Desa Tanjung Type D. Penelitian ini meninjau pekerjaan pasangan dinding. Bahan material yang diamati dan dihitung guna membandingkan koefisien lapangan dengan koefisien Standar Nasional Indonesia. Harga satuan material yang dipakai adalah harga satuan yang mengacu pada harga aktual. Dalam penelitian ini mengukur koefisien bahan dan harga satuan yang di kerjakan pada pekerjaan Revitalisasi Pasar Rakyat Desa Tanjung Type D. Tujuan Penelitian pada Penelitian ini; Untuk dapat mengetahui besarnya nilai koefisien analisis harga satuan bahan material pada pekerjaan pasangan dinding bata. Untuk mengetahui perbandingan koefisien harga satuan lapangan dengan koefisien harga satuan Standar Nasional Indonesia (SNI 2016). Berdasarkan pengamatan di lapangan, didapatkan besarnya koefisien harga satuan material dinding dan plesteran pada Pekerjaan Revitalisasi Pasar Rakyat Desa Tanjung Type D adalah Koefisien harga satuan material untuk pekerjaan $1 \mathrm{~m}^{2}$ pasangan dinding bata adalah: 63 Bata,10,569 Kg Portland Cement (PC), 0,0395 $\mathrm{m}^{3}$ Pasir, dan 5,284 1 air. Koefisien harga satuan material untuk pekerjaan $1 \mathrm{~m}^{2}$ plesteran dinding bata adalah: 6,171 Kg Portland Cement (PC), 0,0237 $\mathrm{m}^{3}$ Pasir, dan 3,086 1 air. Perbandingan Harga Material dinding dan plesteran untuk Pekerjaan Revitalisasi Pasar Rakyat Desa Tanjung Type D adalah sebagai berikut : Pekerjaan Pasangan Dinding Bata Bangunan Utama harga total analisa di Lapangan lebih kecil di bandingkan SNI 2016 dengan selisih Rp. 4.694.581,92 . Pekerjaan Plesteran Dinding Bata Bangunan Utama harga total analisa di Lapangan lebih kecil di bandingkan SNI 2016 dengan selisih Rp. 331.365,60 .
\end{abstract}

Kata Kunci: Harga Satuan Pekerjaan, AHSP 2016, Bahan Material, SNI 2016

\section{PENDAHULUAN}

Dalam pelaksanaan suatu kegiatan konstruksi, masalah yang berkaitan dengan tenaga kerja, upah dan bahan merupakan hal penting yang perlu diperhitungkan. Pekerjaan sekecil apapun apabila tidak didukung dengan tenaga kerja yang berkemampuan baik dan bahan material yang bermutu baik, tidak akan memberikan hasil yang maksimal dan memuaskan dalam sebuah kegiatan konstruksi. Bahkan akibat penggunaan bahan material konstruksi yang kurang tepat bisa mengakibatkan kerugian yang besar pada kegiatan konstruksi.

Di dalam menganalisa harga satuan bahan material digunakan suatu metode yaitu metode SNI (Standar Nasional Indonesia). Prinsip mendasar pada metode SNI adalah daftar koefisien bahan, upah kerja dan alat sudah ditetapkan. Sedangkan dalam menganalisa upah berdasarkan produktivitas digunakan metode pengamatan langsung. Metode ini digunakan untuk mengetahui kondisi yang sebenarnya terjadi di lapangan.

\section{Landasan Teori}

Analisa Harga Satuan Pekerjaan

Analisa harga satuan pekerjaan adalah suatu cara perhitungan harga satuan pekerjaan konstruksi yang dijabarkan dalam perkalian kebutuhan bahan bangunan, upah kerja, dan peralatan dengan harga bahan bangunan, standar pengupahan pekerja dan harga sewa/beli peralatan untuk menyelesaikan per satuan pekerjaan konstruksi.

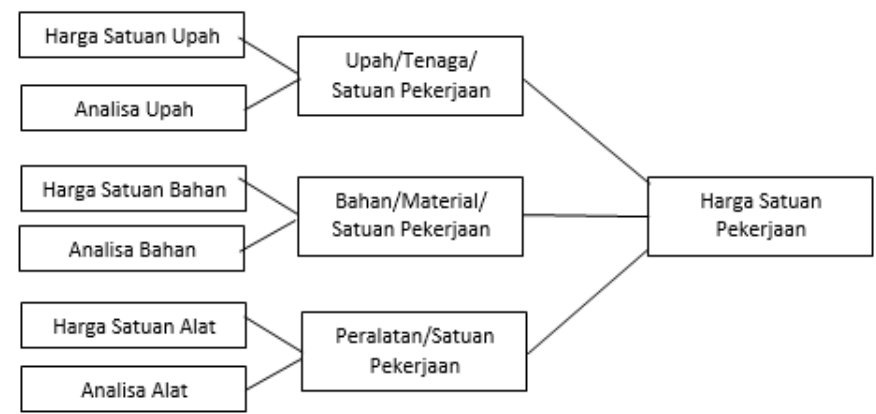

Sumber: Ibrahim, Rencana dan Estimate Real of Cost, Jakarta, 1993

Gambar 1. Skema Harga Satuan Pekjerjaan 
Dalam skema diatas dijelaskan bahwa untuk mendapatkan harga satuan pekerjaan maka harga satuan bahan, harga satuan tenaga, dan harga satuan alat harus diketahui terlebih dahulu yang kemudian dikalikan dengan koefisien yang telah ditentukan sehingga akan didapatkan perumusan sebagai berikut :

Upah : harga satuan upah x koefisien (analisa upah)

Bahan : harga satuan bahan $\mathrm{x}$ koefisien (analisa bahan)

Alat : harga satuan alat $\mathrm{x}$ koefisien (analisa alat)

maka didapat :

HARGA SATUAN PEKERJAAN = UPAH + BAHAN + PERALATAN

\section{Analisa Bahan dan Upah}

Yang dimaksud dengan analisa bahan suatu pekerjaan, ialah yang menghitung banyaknya/volume masingmasing bahan, serta besarnya biaya yang dibutuhkan. Sedangkan yang dimaksud dengan analisa upah suatu pekerjaan ialah, menghitung banyaknya tenaga yang diperlukan, serta besarnya biaya yang dibutuhkan untuk pekerjaan tersebut. (H.bachtiar,1993)

\section{Koefisien Harga Bahan Material}

Koefisien harga bahan material adalah suatu nilai yang berupa faktor pengali untuk satuan harga bahan material. Angka-angka koefisien yang terdapat dalam buku analisa terdiri dari pecahan-pecahan atau angka-angka satuan untuk bahan material. Kedua faktor tersebut adalah untuk menganalisa harga (biaya) yang diperlukan dalam membuat harga satuan pekerjaan bangunan. Dari berbagai asumsi dan hasil pengamatan lapangan yang dilakukan oleh para ahli dan pihak terkait maka terciptalah suatu analisa baru tentang koefisien harga satuan dengan berbagai versi.

\section{Daftar Harga Satuan Bahan Material}

Istilah yang harus dipahami dalam penyusunan anggaran biaya kegiatan pekerjaan pada bahasan ini adalah Harga Satuan Bahan.

Di bawah ini dijelaskan tersebut, sesuai dengan contoh cara menghitung harga satuan pekerjaan untuk $1 \mathrm{~m}^{3}$ pasang beton dengan campuran 1 PC : 2 Pasir : 3 Kerikil (disesuaikan daftar harga satuan bahan dan upah pada daerah Muaro Jambi)

- Daftar Harga Satuan Bahan

Kerikil (Agregat Kasar) Rp. $350.000 / \mathrm{m}^{3}$

Pasir (Agregat Halus) Rp. $200.000 / \mathrm{m}^{3}$

Semen Tipe I (50 kg) Rp. $70.000 /$ zak

Sumber: Toko Material sekitar Muaro Jambi, 2018

\section{Analisa Standar Nasional Indonesia}

Dalam tiap jenis pekerjaan yang terdapat dalam analisa ini tercantum nilai koefisien yang paten.

Ada dua macam kelompok angka koefisien dalam analisa yaitu:

1. Pecahan atau angka satuan untuk bahan.

2. Pecahan atau angka satuan untuk upah kerja

Pecahan atau angka satuan tersebut digunakan untuk:

a. Kalkulasi bahan yang dibutuhkan.

b. Kalkulasi upah kerja yang mengerjakan.

Dalam analisa SNI kelompok angka koefisien hanya terdiri dari pecahan angka satuan bahan dan untuk satuan upah digunakan satuan yang dikeluarkan oleh Dinas Kimpraswil. Berikut dijelaskan satuan bahan untuk $1 \mathrm{~m}^{3}$ pasangan beton K-100 berdasarkan analisa SNI (Badan Standarisasi Nasional, 2016).

$247 \mathrm{~kg} \mid$ Semen Tipe I (1 kg) Rp. $1.400=$ Rp. 345.800,00

$0,6207 \mathrm{~m}^{3}$ | Pasir (Agregat Halus) Rp. $200.000=$ Rp. 124.142,86

$0,74 \mathrm{~m}^{3} \mid$ Kerikil (Agregat Kasar) Rp. $350.000=$ Rp. 259.000,00

$215 l \mid$ Air Rp. $21=$ Rp. $4.515,00+$

Bahan = Rp. 733.457,86

Sumber: Toko Material sekitar Muaro Jambi, 2018 


\section{Analisa Bahan Material}

Dalam menentukan koefisien harga bahan maka diperlukan suatu analisis bahan material. Untuk analisis bahan satuan analisa yang digunakan terdiri dari $\mathrm{m}^{3}$ (meter kubik) untuk menghitung $\mathrm{m}^{2}$ (meter persegi) untuk menghitung luas, $\mathrm{m}^{1}$ (meter) untuk menghitung panjang.

\section{Harga Satuan Bahan}

Yang dimaksud dengan bahan atau material adalah besarnya jumlah bahan yang dibutuhkan untuk menyelesaikan bagian pekerjaan dalam satu kesatuan pekerjaan. Memasang besi beton polos $1 \mathrm{Kg}$ diperlukan bahan.

$1,0500 \mathrm{~kg}$ | Besi beton polos

$0,0150 \mathrm{~kg}$ | Kawat beton

Andai volume memasang besi beton polos bukan $1 \mathrm{~kg}$, melainkan sejumlah 20,65 kg, maka, jumlah bahan yang dibutuhkan sebagai berikut:

Besi beton polos $=20,65 \times 1,05 \mathrm{~kg}=21,683 \mathrm{~kg}$

Kawat beton $=20,65 \times 0,015 \mathrm{~kg}=0,31 \mathrm{~kg}$

Analisa bahan suatu pekerjaan adalah menghitung banyaknya /volume masing-masing bahan, serta besarnya biaya yang dibutuhkan. Dari uraian pasangan besi beton polos $1 \mathrm{~kg}$ diatas, jika dimasukkan harga satuan maka didapat harga satuan bahan.

$1,0500 \mathrm{~kg}$ | Besi beton polos Rp. $12.000=$ Rp. 12.600,00

$0,0150 \mathrm{~kg}$ | Kawat beton Rp. $18.000=$ Rp. 270,00

\section{METODE}

Adapun tahapan dari penelitian ini adalah sebagai berikut:

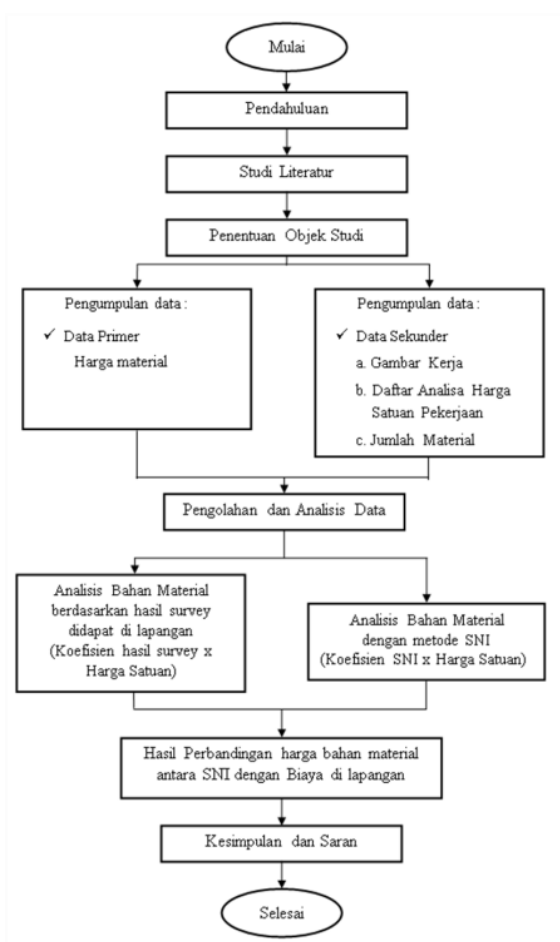

Sumber: Hasil Analisa 2019

Gambar 2. Bagan Alir Penelitian

\section{Pengumpulan Data}

Pengumpulan data ini diperoleh dari survey langsung di lapangan dan dari instansi terkait. Data-data yang dimaksudkan adalah data primer dan data sekunder sebagai berikut :

1. Data Primer

Dimana data tersebut diperoleh langsung dari lapangan pekerjaan konstruksi bangunan Revitalisasi Pasar

Tanjung. Data inilah yang nantinya akan digunakan untuk menghitung besarnya angka koefisien bahan material.

Adapun data primer menggunakan metode sebagai berikut :

a. Harga Bahan Material

Pendataan nilai harga bahan material yang terdapat pada kegiatan pekerjaan Revitalisasi Pasar Rakyat Desa Tanjung Type D di dapat berdasarkan hasil survei Toko bahan Material di Muaro Jambi. 
b. Untuk Pekerjaan Dinding Bata dibutuhkan 10,65 ember adukan mortar untuk mengerjakan $1 \mathrm{~m}^{2}$.

c. Untuk Pekerjaan Plesteran Dinding Bata dibutuhkan 6,35 ember adukan mortar untuk mengerjakan $1 \mathrm{~m}^{2}$.

d. Volume Ember adukan mortar yang digunakan kapasitas 5 Liter.

$$
\begin{aligned}
& 1 / 3 \times 3,14 \times \mathrm{t} \times\left(\mathrm{R}^{2}+(\mathrm{R} \times \mathrm{r})+\mathrm{r}^{2}\right) \\
& =1 / 3 \times 3,14 \times 17 \times\left(12^{2}+(12 \times 8)+8^{2}\right) \\
& =5409,173 \mathrm{~cm}^{3}=0,0054 \mathrm{~m}^{3}
\end{aligned}
$$

Sumber : Hasil Analisa 2019

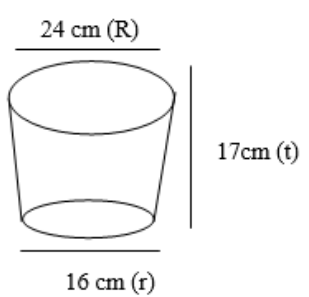

Gambar 3. Ilustrasi Ember

2. Data Sekunder

Data yang didapat dari instansi terkait maupun dari referensi yang diperlukan yang diperoleh berdasarkan pengalaman lapangan yang sudah dilakukan oleh tenaga ahli. Di sini disajikan data sekunder utama yaitu daftar analisa bahan material Standar Nasional Indonesia.

Adapun data sekunder antara lain :

a. Gambar Kerja

Gambar Kerja di dapat dari pihak konsultan perencana dan juga kontraktor pelaksana pada kegiatan pekerjaan Revitalisasi Pasar Rakyat Desa Tanjung Type D.

b. Analisa Harga Satuan Pekerjaan

Analisa Harga Satuan Pekerjaan atau Rencana Anggaran Biaya (RAB) di dapat dari pihak konsultan perencana pada kegiatan pekerjaan Revitalisasi Pasar Rakyat Desa Tanjung Type D.

c. Jumlah Material

Jumlah bahan Material yang terdapat pada kegiatan pekerjaan Revitalisasi Pasar Rakyat Desa Tanjung Type D di dapat berdasarkan Data yg didapat dari Konsultan.

d. Volume Pekerjaan Dinding Bata Bangunan Utama 679,98 $\mathrm{m}^{2}$.

e. Volume Pekerjaan Plesteran Dinding Bangunan Utama $2.116 \mathrm{~m}^{2}$.

\section{HASIL DAN PEMBAHASAN}

Perhitungan Koefisien Material

Perhitungan koefisien Bahan Material didapat setelah melakukan survey pengamatan dan penelitian di lapangan. Pada penelitian ini jenis pekerjaan yang diteliti adalah pekerjaan pemasangan dinding batu bata dan plesteran dinding di lokasi Pasar Tanjung.

\section{Perbandingan Koefisien Material di Lapangan dan SNI Tahun 2016}

Dari hasil perhitungan diatas, maka dapat dilakukan perbandingan koefisien bahan dilapangan dengan SNI

\begin{tabular}{|c|c|c|c|c|c|}
\hline \multirow[t]{2}{*}{ No. } & \multirow[t]{2}{*}{ Jenis Bahan } & \multicolumn{4}{|c|}{$\begin{array}{l}\text { Pekerjaan Revitalisasi Pasar } \\
\text { Rakyat Desa Tanjung TYPE D }\end{array}$} \\
\hline & & \multicolumn{2}{|c|}{ SNI } & \multicolumn{2}{|c|}{ Lapangan } \\
\hline I. & \multicolumn{5}{|c|}{ Pekerjaan Pasangan Dinding Bata Bangunan Utama } \\
\hline 1. & Bata & 70 & Buah & 63 & Buah \\
\hline 2. & Portland Cement (PC) & 11,5 & $\mathrm{Kg}$ & 10,569 & $\mathrm{Kg}$ \\
\hline 3. & Pasir & 0,043 & $\mathrm{~m}^{3}$ & 0,0395 & $\mathrm{~m}^{3}$ \\
\hline 4. & Air & 5,75 & $l$ & 5,284 & $l$ \\
\hline II. & \multicolumn{5}{|c|}{ Pekerjaan Plesteran Dinding Bata Bangunan Utama } \\
\hline 1. & Portland Cement (PC) & 6,24 & $\mathrm{Kg}$ & 6,171 & $\mathrm{Kg}$ \\
\hline 2. & Pasir & 0,024 & $\mathrm{~m}^{3}$ & 0,0237 & $\mathrm{~m}^{3}$ \\
\hline 3. & Air & 3,12 & $l$ & 3,086 & $l$ \\
\hline
\end{tabular}
tahun 2016, berikut koefisien bahan dilapangan dan SNI 2016.

Tabel 1 Nilai Koefisien Material di Lapangan dan SNI Tahun 2016

Sumber : Data Olahan Tahun 2019 
Elvira Handayani, M. Nuklirullah dan El Gafur, Analisa Perbandingan Koefisien Harga Satuan Bahan Material Pekerjaan Revitalisasi Pasar Rakyat Desa Tanjung Type D berikut :

Koreksi atau tingkat perbedaan yang terjadi antara koefisien lapangan dengan koefisien SNI tahun 2016 sebagai

1. Pekerjaan Pasangan Dinding Bata Bangunan Utama

- Bata $63 / 70=0,9$

- Semen 10,569 / 11,5 = 0,919

- Pasir 0,0395 / 0,043 = 0,919

- Air 5,284 / 5,75 = 0,919

2. Pekerjaan Plesteran Dinding Bata Bangunan Utama

- Semen 6,171 / 6,24 =0,989

- Pasir 0,0237 / 0,024=0,988

- Air 3,086 / 3,12 = 0,989

Dari Perhitungan diatas, maka dapat diperoleh perbandingan koefisien SNI tahun 2016 dengan koefisien di lapangan.

Tabel 2. Perbandingan Koefisien Material di Lapangan dan SNI Tahun 2016

\begin{tabular}{|c|c|c|c|}
\hline \multirow[t]{2}{*}{ No. } & \multirow[t]{2}{*}{ Jenis Bahan } & \multicolumn{2}{|c|}{$\begin{array}{l}\text { Pekerjaan Revitalisasi Pasar } \\
\text { Rakyat Desa Tanjung TYPE D }\end{array}$} \\
\hline & & SNI & Lapangan \\
\hline I. & \multicolumn{3}{|c|}{ Pekerjaan Pasangan Dinding Bata Bangunan Utama } \\
\hline 1. & Bata & 1 & 0,900 \\
\hline 2. & Portland Cement (PC) & 1 & 0,919 \\
\hline 3. & Pasir & 1 & 0,919 \\
\hline 4. & Air & 1 & 0,919 \\
\hline II. & \multicolumn{3}{|c|}{ Pekerjaan Plesteran Dinding Bata Bangunan Utama } \\
\hline 1. & Portland Cement (PC) & 1 & 0,989 \\
\hline 2. & Pasir & 1 & 0,988 \\
\hline 3. & Air & 1 & 0,989 \\
\hline
\end{tabular}

Sumber : Data Olahan Tahun 2019

\section{Harga Satuan Material Dinding dan Plesteran Koefisien Lapangan}

Berikut perhitungan harga satuan material sesuai dengan koefisien berdasarkan pengamatan di lapangan.

Tabel 3. Harga Satuan Material $1 \mathrm{~m}^{2}$ Dinding dan Plesteran di Lapangan

\begin{tabular}{|c|c|c|c|c|c|c|c|}
\hline No. & Jenis Bahan & \multicolumn{2}{|c|}{ Koefisien } & & $\begin{array}{l}\text { ga Satuan } \\
\text { (Rp) }\end{array}$ & \multicolumn{2}{|c|}{$\begin{array}{c}\text { Jumlah Harga } \\
(\mathrm{Rp})\end{array}$} \\
\hline I. & \multicolumn{7}{|c|}{ Pekerjaan Pasangan Dinding Bata Bangunan Utama } \\
\hline 1. & Bata & 63 & Buah & Rp. & 700,00 & Rp. & $44.100,00$ \\
\hline 2. & Portland Cement (PC) & 10,569 & $\mathrm{Kg}$ & Rp. & $1.400,00$ & Rp. & $14.796,60$ \\
\hline 3. & Pasir & 0,0395 & $\mathrm{~m}^{3}$ & Rp. & $200.000,00$ & Rp. & $7.900,00$ \\
\hline 4. & Air & 5,284 & $l$ & Rp. & - & Rp. & \\
\hline \multicolumn{6}{|c|}{ Jumlah Harga Bahan } & Rp. & $66.796,60$ \\
\hline II. & \multicolumn{7}{|c|}{ Pekerjaan Plesteran Dinding Bata Bangunan Utama } \\
\hline 1. & Portland Cement (PC) & 6,171 & $\mathrm{Kg}$ & $\mathrm{Rp}$. & $1.400,00$ & Rp. & $8.639,40$ \\
\hline 2. & Pasir & 0,0237 & $\mathrm{~m}^{3}$ & Rp. & $200.000,00$ & Rp. & $4.740,00$ \\
\hline 3. & Air & 3,086 & $l$ & Rp. & - & Rp. & - \\
\hline \multicolumn{6}{|c|}{ Jumlah Harga Bahan } & Rp. & $13.379,40$ \\
\hline
\end{tabular}

Sumber : Data Olahan Tahun 2019

\section{Perbandingan Harga Satuan di Lapangan dengan SNI 2016}

Setelah dilakukan perhitungan koefisien Material sesuai dengan dilapangan dan kemudian didapat perbanding koefisien dilapangan dengan SNI 2016, selanjutnya dilakukan perbandingan harga dengan menggunakan koefisien yang telah diamati di lapangan dengan koefisien SNI 2016. Agar dapat diketahui selisih harga satuan kegiatan yang ada di lapangan dengan SNI 2016.

\section{Perbandingan Analisa Anggaran Biaya Material Berdasarkan Pengamatan di Lapangan dengan Metode SNI}

Berdasarkan hasil perhitungan didapatkan perbandingan antara Analisa Anggaran Biaya material di Lapangan dengan SNI sebagai berikut: 
Elvira Handayani, M. Nuklirullah dan El Gafur, Analisa Perbandingan Koefisien Harga Satuan Bahan Material Pekerjaan Revitalisasi Pasar Rakyat Desa Tanjung Type D

Tabel 4 Perbandingan Analisa Anggaran Biaya Dinding dan Plesteran Pasar Tanjung berdasarkan Koefisien Lapangan dan SNI 2016.

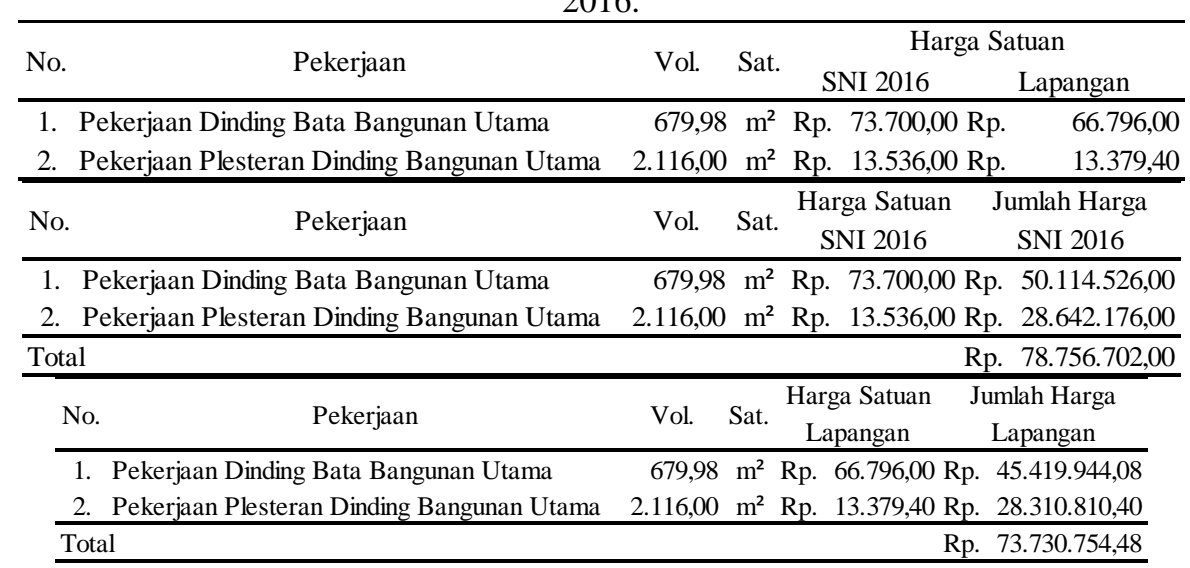

Sumber : Data Olahan Tahun 2019

\section{SIMPULAN}

Berdasarkan pengamatan di lapangan, didapatkan besarnya koefisien harga satuan material dinding dan plesteran pada Pekerjaan Revitalisasi Pasar Rakyat Desa Tanjung Type D :

1. Koefisien harga satuan material untuk pekerjaan $1 \mathrm{~m}^{2}$ pasangan dinding bata adalah:

- 63 Bata;

- $10,569 \mathrm{Kg}$ Portland Cement (PC);

- $0,0395 \mathrm{~m}^{3}$ Pasir; dan

- 5,284 $l$ air.

2. Koefisien harga satuan material untuk pekerjaan $1 \mathrm{~m}^{2}$ plesteran dinding bata adalah:

- $6,171 \mathrm{Kg}$ Portland Cement (PC);

- $0,0237 \mathrm{~m}^{3}$ Pasir; dan

- 3,086 l air.

3. Perbandingan Harga Material dinding dan plesteran untuk Pekerjaan Revitalisasi Pasar Rakyat Desa Tanjung Type D adalah sebagai berikut :

a. Pekerjaan Pasangan Dinding Bata Bangunan Utama harga total analisa di Lapangan lebih kecil di bandingkan SNI 2016 dengan selisih Rp. 4.694.581,92 .

b. Pekerjaan Plesteran Dinding Bata Bangunan Utama harga total analisa di Lapangan lebih kecil di bandingkan SNI 2016 dengan selisih Rp. 331.365,60.

\section{DAFTAR PUSTAKA}

Azwar, Syifuddin. 2007. Sikap Manusia Teori dan Pengukurannya. Yogyakarta: Pustaka Pelajar.

Bachtiar, H. Ibrahim. 1993. Rencana dan Estimate Real of Cost. Jakarta: Bumi Aksara.

Dinas Pekerjaan Umun dan Perumahan Rakyat. 2016. Daftar Harga Upah dan Bahan; Daftar Analisa Harga Satuan Pekerjaan. Jambi.

Djojowirono, Sugeng. 1984. Manajemen Konstruksi I. Yogyakarta: Andi.

Sastraatmadja, Soedrajat A. 1993. Analisa Anggaran Biaya Pelaksanaan. Bandung: Nova.

Soeharto, Imam 1997. Manajemen Proyek Dari Konseptual Sampai Operasional, Penerbit Erlangga - Jakarta

Gambar Kerja. 2018. Revitalisasi Pasar Rakyat Desa Tanjung Type D : CV. Jasco 